\title{
GROWTH, NODULATION, YIELD AND MINERAL TISSUE CONTENT OF PEANUT IN RESPONSE TO FOLIAR AND COATING APPLICATION OF HUMIC ACID AND PLANT GROWTH -PROMOTING RHIZOBACTERIA
}

\author{
El-Syed F.R ${ }^{1}$ - Hoda. A.G ${ }^{1}$ and- Yassen .M . $\mathrm{Y}^{2}$ \\ 1 Environmental Studies\& Research Institute (ESRI), Sadat City University, Egypt. \\ 2 Genetic Engineering Institute, Sadat City University, Egypt.
}

\section{$\mathrm{T}$}

ABSTRACT

he aim of this investigation was to study the effect of adding humic acid and plant growth promoting rhizobacteria (PGPR), as foliar and coating application on plant growth, nodulation status and yield of peanut under field conditions. Results indicate that, using microbial inoculation with Brady rhizobium as single inoculation and coinoculation with PGPR (Azospirillum sp. + Bacillus polymyxa + Serratia marcescens) as mixed inocul, conjugated with humic acid at two rates $3 \mathrm{~L} /$ fed and $5 \mathrm{~L} /$ fed. signicantly increased shoot dry weight, nodulation status and yield of peanut plant under coating and foliar applications. Incorporation of humic acid as foliar and coating application led to highest significant for all parameters above control. Also, coating application method was higher than foliar application. Shoot mineral content of N,P and K were increased by using coinoculation and addition of humic acid.

Key words: Plant growth -promoting Rhizobacteria, nodulation, coating and foliar application.

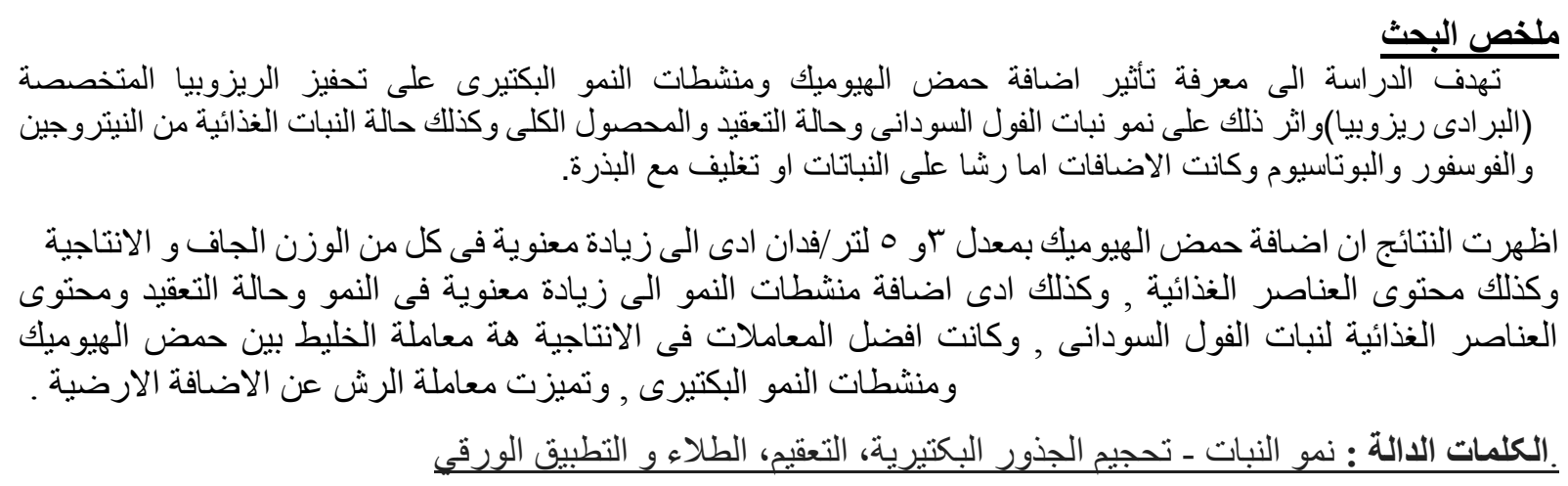

\section{INTRODUCTION}

Groundnut or Peanut (Arachis hypogaea L.) is considered to be one of the most important edible legume crops in Egypt, due to its seeds has high nutritive value for human and the produced cake as well as the green leafy hay for livestock. In addition, its seeds oil is very important for industrial purposes. Groundnut seeds contain about 50\% oil, 25-30\% protein, 20\% carbohydrates and 5\% fiber (Fageria et al., 1997). Due to the intensive farming, Egypt is known as a heavy consumer of chemical fertilizers. This intensive farming has caused negative effects on soil environment over the past decades, i.e. loss of soil organic matter, soil erosion and water pollution. The use of chemical fertilizers has been doubled during the last two decades. Thus the coincident application of organic manures and bio-fertilizers is frequently recommended, firstly for improving biological, physical and chemical properties of soil and secondary to get high and clean agricultural yield produced free from undesirable high doses of heavy metals and other pollutants.

\section{Issued by Environmental Studies and Researches Institute (ESRI), University of Sadat City}


Application of mineral $\mathrm{N}$ fertilizers has increased in the world agriculture, but too much of such nitrogen form can lead to a terrestrial and aquatic pollution and needs to be reduced (Mengel et al., 2001). Biofertilizers are alternatives as to increase soil productivity and improve plant growth in a sustainable agriculture regime. Biological nitrogen fixation (BNF) is the most important biochemical reaction for life on earth (Bohlool et al., 1992).

Plant growth promoting rhizobacteria (PGPR) have the ability to enhance plant growth either directly, by phytohormons production, $\mathrm{N}_{2}$-fixation and siderophores production...ect., or indirectly, through biological control of pathogens or induction of host defense mechanisms (Dey et al 2004; Zahir et al 2004 and Verma et al 2010).

Enhancement of nodulation and biological nitrogen fixation by co-inoculation legumes with PGPR are becoming a practical way to improve nitrogen availability in sustainable agricultural production system (Bai et al 2002 and Abdel-Wahab et al 2008). The most commonly implicated mode to stimulate of legume-Rhizobium sympiosis is phytohormones inducing stimulation of root growth, to provide more sites for rhizobial infection and nodulation (Vessey and Buss, 2002).

One of the used organicmineral fertilizers is humic acid. Humic acid is one of the major components of humic substances. Humic matter is formed through the chemical and biological humification of plant and animal matter and through the biological activities of microorganisms (Anonymous, 2010). Under water stress, foliar fertilization with humic molecules increased leaf water retention and the photosynthetic and antioxidant metabolism (Fu Jiu, 1995). Several researchers, , Neri et al.(2002) and EI-Desuki (2004) concluded that humic acid as foliar sprays enhanced growth nutrient uptake and yield and improved the quality of the production of some crops, this may be decrease the N,P,K applied as soil application which decrease pollution and costs.

Therefore, the objective of this work is to investigate the effect of organic and biofertilization on productivity and quality of groundnut seeds, improvement of physical and chemical properties of new reclaimed soils.

\section{MATERIAL AND METHODS}

\subsection{MICROORGANISMS USED}

Bradyrhizobium spp. ( strain USDA 3456) and mixed of PGPR (Azospirillum sp.+ Bacillus polymyxa + Serratia marcescens) were kindly obtained from the Biofertilizers Production Unit, Agric. Microbiology. Dept., Soils, Water and Environ. Res. Inst. (SWERI), Giza, Egypt.

\subsection{HUMIC ACID}

Humic acid, applied at two rates of $3 \mathrm{~L}$ and $5 \mathrm{~L} /$ fad. Application the coating with sowing but the foliar at three equal doses applied at 30, 45, 60 days from sowing as a foliar application.

\subsection{FIELD EXPERIMENT}

Field experiment was conducted in a private farm at Meat Fares, perket El-sabaa ,Menoufia Governorate, Egypt in a sandy loam that contain ,68.9 sand ,24.85 silt and 6.25 clay, pH was 7.13 in soil pastand E.C $0.36 \mathrm{dSm}^{-1}$,during summer season 2016 to study the effect of inoculation with Bradyrhizobium individually or mixed with (PGPR) and or humic acid at two method, coating and foliar applications, on growth, nodulation status, and productivity of peanut (groundnut) as well as mineral content in plant tissue. Groundnut seeds variety 
(Ismaeilia 1 ) were kindly provided by the Field Crops Research Institute, Agricultural Research Center (ARC), Giza, Egypt.

A sample weighing $0.2 \mathrm{~g}$ of the dried fine materials of peanut shoots were digested with a mixture of $10 \mathrm{ml}$ concentrated $\mathrm{H}_{2} \mathrm{SO}_{4}$ and $\mathrm{HClO}_{4}$ (at a ratio 3:1), on a sand hot plate (at approximately $270{ }^{\circ} \mathrm{C}$ ), until the digest become clear. The digest was then diluted to $100 \mathrm{ml}$ with distilled water. The contents of N, P \& K (\%) in the diluted digest were determined following the methods stated by (Cottenie et al., 1982). The data was later statistically analyzed, as "LSD" (Gomez and Gomez, 1984).

\section{RESULT AND DISCUSSION}

\subsection{SHOOT DRY WEIGHT}

Data in Table (1) indicate that using microbial inoculation with Brady rhizobium as single inoculation and coinoculation with PGPR ( Azospirillum sp. + Bacillus polymyxa + Serratia marcescens) as mixed incula, humic acid at two rates $3 \mathrm{~L} / \mathrm{fed}$ and $5 \mathrm{~L} /$ fed. signicantly increased shoot dry weight of peanut plant under coating and foliar applications. Also, coating application was more higher than foliar application when gave the main $18.87 \mathrm{~g}$ compared foliar which gave $17.23 \mathrm{~g}$ at 45 day after planting. Also, the date in Table, 1 declared that, incorporation of humic acid improvement the growth of shoot and increased shoot dry weight at 45 and 75 day after sowing.

Table (1) Effect of microbial inoculation and humic acid on shoot dry weight of peanut.

\begin{tabular}{|c|c|c|c|c|c|c|}
\hline \multirow{2}{*}{ Treatment } & \multicolumn{2}{|c|}{ After 45 day from planting } & \multicolumn{3}{c|}{ After 75 from planting } \\
\cline { 2 - 7 } & Coting & Foliar & Mean & Coting & Foliar & Mean \\
\hline T1 & 13.59 & 12.45 & 13.02 & 15.40 & 14.15 & 14.77 \\
\hline T2 & 19.56 & 18.20 & 18.88 & 21.90 & 20.08 & 20.99 \\
\hline T3 & 17.48 & 15.80 & 16.64 & 18.10 & 17.55 & 17.82 \\
\hline T4 & 16.48 & 14.83 & 15.65 & 19.30 & 17.97 & 18.63 \\
\hline T5 & 18.61 & 17.05 & 17.83 & 23.00 & 21.18 & 22.09 \\
\hline T6 & 21.87 & 20.05 & 20.96 & 25.90 & 23.56 & 24.73 \\
\hline T7 & 24.47 & 22.25 & 23.36 & 28.40 & 26.09 & 27.24 \\
\hline Mean & 18.87 & 17.23 & - & 21.73 & 20.08 & - \\
\hline L.S.D. at 5\% & 0.278 & 0.792 & - & 1.45 & 1.13 & - \\
\hline
\end{tabular}

T1: Control, T2: Recommended dose of mineral fertilizers, $\mathrm{T}$ 3: Brady rhizobium, T4:Br.+HA3L, T 5: Br,+51,

T 6: Br+ PGPR and T7: Mixed of all

It was also observed that, the mixed of all treatment (T7) gave the extra increases in shoot dry weights under two methods applications at 45 and 75 day after planting when gave 24.47, $22.25,28.40$ and 27.24, respectively. These increases in shoot dry weights might be due to increase in vegetative growth, which resulted in improvement the nutrient uptake with adding microbial inoculation and humic acid. Hence, the inoculation of Brady rhizobium and PGPR 
save N2-Fixation, P solubilization, plant growth regulators such as phytohormons and vitamins, and this growth regulators influence plant growth i. e. increased root surface area, respiration rate and metabolism improving mineral and water uptake. These results led to increase in shoot dry weights of plant. This results agreement with those recorded by El-Howeity (2004). Also, Stockwell and Stack (2007) and Sindhu et al. (2009) mentioned that, microorganisms inhabiting rhizosphere of legumes may benefit plants in a variety of ways, like increased recycling, mineralization and uptake of nutrients, synthesizing vitamins, amino acids, auxins, gibberlins and plant growth regulating substances, reducing metal toxicity (bioremediation) in contaminated soils, antagonism with potential plant pathogens through competition and development of amensal relationships based on production of antibiotics, siderophores, and/or hydrolytic enzymes.

\subsection{NODULATION STATUS}

Data presented in Table (2) demonstrated that, the inoculation with specific rhizobia with Brady rhizobium significantly enhanced nodulation status, number and weight of nodules/plant at any application methods, increases in number of nodules were $124.66 \%$ and $144.15 \%$ above control. Also, increases in weight of nodules were $115.82 \%$ and $119.42 \%$ above control, respectively. However, Coating method was more effective than foliar application method with number and weight of nodules, when gave 66.23, 313.59, 55.90 and 304.16, respectively. Likewise, coinoculation with Brady rhizobium and PGPR was more effective than single inoculation or humic acid addition. So, the application of all treatment T7 led to significant increases and scored higher increases and was more effective compared to other treatments. Humic and PGPR application stimulating legume -rhizobia symbiosis. Since, rhizobium infection tack place by the formation of infection threads in the root hair (Gage and Margolin 2000), the stimulation of a greater infect able root hair cells, may provide more sites for infection and nodulation.

Table (2) Effect of microbial inoculation and humic acid application on nodulation status

\begin{tabular}{|c|c|c|c|c|c|c|}
\hline \multirow{2}{*}{ Treatment } & \multicolumn{3}{|c|}{ Number of nodules/plant } & \multicolumn{3}{c|}{ Weight of nodules /plant(g) } \\
\cline { 2 - 7 } & Coting & Foliar & Mean & Coting & Foliar & Mean \\
\hline T1 & 27.00 & 19.66 & 23.33 & 153.26 & 151.20 & 152.23 \\
\hline T2 & 13.66 & 16.00 & 14.83 & 144.33 & 138.20 & 141.26 \\
\hline T3 & 60.66 & 48.00 & 54.33 & 326.46 & 333.76 & 330.11 \\
\hline T4 & 70.33 & 64.00 & 67.16 & 361.50 & 337.97 & 349.73 \\
\hline T5 & 82.33 & 75.00 & 78.66 & 373.86 & 372.20 & 373.03 \\
\hline T6 & 93.33 & 84.33 & 88.83 & 406.06 & 393.50 & 399.78 \\
\hline T7 & 116.33 & 84.32 & 100.32 & 429.63 & 407.16 & 418.39 \\
\hline Mean & 66.23 & 55.90 & - & 313.59 & 304.16 & - \\
\hline L.S.D. at 5\% & 5.49 & 9.51 & - & 33.66 & 13.72 & - \\
\hline
\end{tabular}

T1: Control, T2: Recommended dose of mineral fertilizers, $\mathrm{T}$ 3: Brady rhizobium, T4:Br.+HA3L, T 5: Br,+51,

T 6: Br+ PGPR and T7: Mixed of all.

\subsection{YIELD PRODUCTIVITY}


Data presented in Table (3) showed the effect of the incorporation biofertilizers and humic acid as coating or foliar application on peanut yield under field conditions. Results indicated that, foliar application was more effective with peanut yield and the weight of 100 seeds but the increases were slight. Irrespective of the adding biofertilizers, inoculation with Brady rhizobium plus half doses of nitrogen fertilizer led to significantly increases in yield and weight of 100 seed yields, when gave increases reached to 33.30 and $6.48 \%$ above control for the mean yield and weight of 100 seed yield. Increases were more pronounced by using coating application than using foliar application, when gave increases reached with coating $(33.59 \&$ $7.53 \%$ ) and reached with foliar (32.99\& $5.44 \%$ ) above control for yield and weight of 100 seed yield, respectively.

Table (3) Effect microbial inoculation and humic acid on peanut yield

\begin{tabular}{|c|c|c|c|c|c|c|c|c|c|}
\hline \multirow{2}{*}{ Treatment } & \multicolumn{3}{|c|}{ Yield (ton/fed.) } & \multicolumn{3}{c|}{ Weight of 100 seeds } & \multicolumn{3}{c|}{ Shelling \% } \\
\cline { 2 - 11 } & Coting & Foliar & Mean & Coting & Foliar & Mean & Coting & Foliar & Mean \\
\hline T1 & 10.33 & 10.70 & 10.51 & 69.93 & 71.60 & 70.76 & 66.40 & 67.20 & 66.80 \\
\hline T2 & 12.30 & 12.43 & 12.36 & 72.76 & 73.26 & 73.01 & 67.04 & 67.29 & 67.16 \\
\hline T3 & 13.80 & 14.23 & 14.01 & 75.20 & 75.50 & 75.35 & 67.05 & 67.61 & 67.33 \\
\hline T4 & 15.06 & 15.10 & 15.08 & 78.43 & 81.53 & 79.98 & 68.26 & 68.93 & 68.59 \\
\hline T5 & 18.10 & 18.66 & 18.38 & 82.36 & 80.67 & 79.61 & 69.13 & 69.12 & 69.12 \\
\hline T6 & 19.23 & 20.33 & 19.78 & 78.56 & 83.13 & 82.74 & 70.23 & 69.91 & 70.00 \\
\hline T7 & 18.20 & 18.90 & 18.55 & 78.05 & 78.91 & 78.48 & 72.98 & 72.97 & 72.90 \\
\hline Mean & 15.29 & 15.80 & - & 76.47 & 77.80 & - & 68.73 & 69.07 & - \\
\hline L.S.D. at 5\% & 0.566 & 0.374 & - & 1.27 & 0.52 & - & 0.3 & 0.169 & - \\
\hline
\end{tabular}

T1: Control, T2: Recommended dose of mineral fertilizers, T 3: Brady rhizobium, T4:Br.+HA3L, T 5: Br, +51 ,

T 6: Br+ PGPR and T7: Mixed of all.

Also, incorporation of humic acid at rate 3 and 51/fed. led to more increases in yield and weight of 100 seed yield over control and above single Brady rhizobium, increases with adding humic conjugated with rhizobia reached to $(43.48 \& 12.90 \%)$ and ( $74.88 \& 12.50 \%)$ above control for yield and weight of 100 seed yield with adding 3 and 5L/fed, respectively.

\subsection{TOTAL CONTENTS OF N, P AND K IN PEANUT SHOOT :}

Data presented in Tables (4and 5 ) showed the total contents of N,P and K in groundnut shoots at 45 and 75 days from sowing were greatly affected by adding treatment of inoculation with Brady rhizobium, Plant growth promoting rhizobacteria (PGPR) and humic acid, foliar or coating application. Results showed that the treatment combination ( $(\mathrm{Br}+50 \% \mathrm{PK}+\mathrm{PGPR}$ $+5 \mathrm{LH}$ ) (T7) was significantly superior effect compared to control and all the other treatment in nitrogen, phosphor and potassium content in shoot at 45 and 75 day from sowing . however, it gave the highest mean 825.3, 133.81 and 735.44 for N,P and $\mathrm{K}$ at 45 day, respectively . Likewise, it gave $963.75,157.12$ and 769.7 for N,P and $\mathrm{K}$ at 75 day after sowing, respectively. Also, coating application was more effective with $\mathrm{N}$ and $\mathrm{K}$ compared to foliar application but foliar application was more for phosphor. As well as, using full doses from mineral fertilizer increased the content of N,P and K contents in peanut shoots at 45 and 75 day, when gave the 
mean value (669.8, 110.55 and 599.43) and (748.70, 125.63 and 654.3) For N,P and K at 45 and 75 day after sowing, respectively.

Table (4) Effect of microbial inoculation and humic acid on mineral contents of shoots at 45 day after sowing.

\begin{tabular}{|c|c|c|c|c|c|c|c|c|c|}
\hline \multirow{2}{*}{ Treatment } & \multicolumn{3}{|c|}{ N } & \multicolumn{3}{c|}{ P } & \multicolumn{3}{c|}{ K } \\
\cline { 2 - 10 } & Coating & Foliar & Mean & Coating & Foliar & Mean & Coating & Foliar & Mean \\
\hline T1 & 402.4 & 362.2 & 382.3 & 53.95 & 58.94 & 56.44 & 330.14 & 311.23 & 320.68 \\
\hline T2 & 696.0 & 643.7 & 669.8 & 107.60 & 113.50 & 110.55 & 618.45 & 580.42 & 599.43 \\
\hline T3 & 545.7 & 497.9 & 521.8 & 76.28 & 81.89 & 79.08 & 493.98 & 488.23 & 491.10 \\
\hline T4 & 527.8 & 474.3 & 501.3 & 74.68 & 79.65 & 77.16 & 476.79 & 466.95 & 471.87 \\
\hline T5 & 622.9 & 559.1 & 591.0 & 91.19 & 92.42 & 91.80 & 546.61 & 537.30 & 541.95 \\
\hline T6 & 755.5 & 686.2 & 720.8 & 106.27 & 117.39 & 111.83 & 645.40 & 636.76 & 641.08 \\
\hline T7 & 870.5 & 780.2 & 825.3 & 129.22 & 137.65 & 133.81 & 753.80 & 717.09 & 735.44 \\
\hline Mean & 631.6 & 571.9 & - & 91.39 & 97.85 & - & 552.03 & 534.00 & - \\
\hline L.S.D. at 5\% & 20.69 & 25.34 & - & 3.05 & 2.28 & & 11.18 & 24.99 & - \\
\hline
\end{tabular}

T1: Control, T2: Recommended dose of mineral fertilizers, $\mathrm{T}$ 3: Brady rhizobium, T4:Br.+HA3L, T 5: Br,+51,

T 6: Br+ PGPR and T7: Mixed of all.

Furthermore, inoculation with Br. Plus half dose from mineral fertilizer cannot replace full doses, but humic acid with microbial inoculation as mixture led to higher increases in nitrogen, phosphor and potassium content in peanut shoot at 45 and 75 day after sowing.

Table (5): Effect of microbial inoculation and humic acid on mineral contents of shoots at 75 day after sowing.

\begin{tabular}{|l|l|l|l|l|l|l|l|l|l|}
\hline \multirow{2}{*}{ Treatment } & \multicolumn{3}{|c|}{ N } & \multicolumn{3}{c|}{ P } & \multicolumn{3}{c|}{ K } \\
\cline { 2 - 11 } & Coating & Foliar & Mean & Coating & Foliar & Mean & Coating & Foliar & Mean \\
\hline T1 & 456.5 & 411.0 & 433.75 & 61.22 & 66.72 & 63.97 & 374.98 & 353.8 & 364.3 \\
\hline T2 & 787.2 & 710.2 & 748.70 & 120.70 & 130.57 & 125.63 & 689.54 & 619.19 & 654.3 \\
\hline T3 & 569.2 & 576.9 & 573.05 & 79.56 & 85.06 & 82.31 & 515.32 & 509.34 & 512.3 \\
\hline T4 & 625.1 & 582.2 & 603.65 & 87.91 & 93.09 & 90.50 & 561.11 & 549.46 & 555. \\
\hline T5 & 764.4 & 694.8 & 729.60 & 112.72 & 114.28 & 113.50 & 675.42 & 664.19 & 669. \\
\hline T6 & 934.1 & 806.1 & 870.10 & 131.05 & 137.87 & 134.46 & 757.99 & 781.52 & 769.7 \\
\hline T7 & 1013.2 & 914.3 & 963.75 & 153.81 & 160.43 & 157.12 & 876.69 & 834.45 & \\
\hline Mean & 735.69 & 670.8 & - & 106.71 & 112.57 & - & 635.91 & 611.18 & \\
\hline L.S.D. at 5\% & 21.18 & 30.44 & - & 5.58 & 3.77 & - & 8.76 & 38.61 & \\
\hline
\end{tabular}


The improvement in nutrient uptake by using plant growth promoting rhizobacteria may be attributed to several mechanisms such as fixing atmospheric nitrogen, producing siderophores that chelate iron and make it available to the plant root, solubilizing minerals such as phosphorus and producing hormones and synthesizing some compounds or enzymes that can develop plant growth. Indirect growth stimulation of plants is also connected with protection them against the effects of phytopathogens. Yet, the bacteria compete for space at the root of pathogens, where they produce chelators (so-called siderophores) which are specific for the $\mathrm{Fe}^{3+}$ ions. Siderophores have a higher affinity for iron than chelators produced by pathogenic microorganisms present in the rhizosphere. Thus, the $\mathrm{Fe}^{3+}$ becomes unavailable for pathogens. PGPR bacteria are also capable of the production of secondary metabolites with antibiotic properties or are antifungal substances, insecticides and immunosuppressants (Kloepper et al 2003, Glick, 2005). The PGPR include free-living soil bacteria that occur in the root zone and endophytic bacteria, colonizing the root cells. The largest group of PGPR bacteria are Pseudomonas, Bacillus, Enterobacter, and Erwinia. Indoleacetic acid (IAA) that is produced by the bacteria may enhance the effects of plant auxin and can directly affect root growth by stimulating cell division and elongation of the plant (Kalitkiewicz and Kepczy nska, 2008).

Islam et al. (2012) revealed that, the biofertilizer Azospirillum strains " BM9" and "BM11" positively affected on N,P and k uptake in rice grain and straw yields as single inoculation, they also, found that the interaction of two strains significantly influenced affected on N,P and K uptake .

\section{REFERENCES}

1. El-Wahab, A.F.M.; G.A.A.Mekhemar; F.Sh.F.Badawi and Heba Sh. Shehata (2008). Enhancement of nitrogen fixation, growth and productivity of Bradyrhizobium-lupin symbiosis via co-inoculation with rhizobacteria in different soil types. J. Agric. Sci., Mansoura Univ., 33: 469-484.

2. Anonymous. (2010). Humic and fulvic acids: The black gold of agriculture? http://www.humintech.com/pdf/humicfulvicacids.pdf (Access date: 10.08.2010).

3. Bai, Y.; A. Souleimanov and D.L. Smith (2002). An inducible activator produced by Serratia proteamaclans strain and its soybean growth promoting activity under greenhouse conditions. J. Exp.Bot., 53:149-502

4. Bohlool, B.B.; Ladha, J.K.; Garrity, D.P. and George, T. (1992). Biological nitrogen fixation for sustainable agriculture: A perspective. Plant and Soil, 141: 1-11.

5. Cottenie, A.; Verloo, M.; Kikens, L.; Velghe, G. and Camerlynck, R. (1982): Analytical Problems and Methods in Chemical Plant and Soil Analysis. Hand book (Ed.A. Cottenie). Gent, Belgium.

6. Dey, R.; K. K. Pal; D.M. Bhatt and S. M. Chauhan (2004). Growth promotion and yield

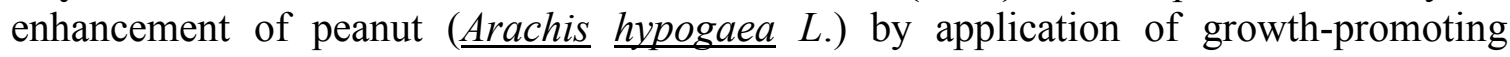
rhizobacteria. Micbiol. Res., 159:371-394.

7. El-Desuki M. (2004). Response of onion plants to humic acid and mineral fertilizers application. Annals of Agric. Sci., Moshtohor, 42(4):1955- 1964.

8. El-Howeity M.A.(2004). Colonization patterns of diazotrophs associated with legume and non-legune crops. Ph.D., Dep. Soil Sci., Fac. Agric., Minufiya Univ., Egypt. 
9. El-Howeity M.A., A.A.Abdalla, Hanaa A. Abo-Kora and M.M.El-Shinnawi (2009). Response of faba bean plants to inoculation with Rhizobium leguminosarium and other Rhizobacteria under three nitrogen levels in newly reclaimed soil. J.Agric. Sci. Mansoura Univ. ,34(6): 7259-7272.

10. Fageria, N. K., V. C. Ballgar and C. A. Johnes (1997). Growth and mineral mutrition of field crops. $2^{\text {nd }}$ Edition. Marcel Dekker. Inc, New York, U.S.A. P:494

11. Fu Jiu C, Dao Qi Y and Quing Sheng W. (1995). Physiological effects of humic acid on drought resistance of wheat (in Chinese), Yingyong Shengtai Xuebao 6, 363-367.

12. Gage D.J and W. Mmargolin (2000). Hanging by a thread: invasion of legume plants by rhizobia. Crrent Opinion in Microbiology., 3:613-617.

13. Glick, B.R. ( 2005). Modulation of plant ethylene levels by the bacterial enzyme ACC deaminase. FEMS Microbiol. Lett. 251, 1-7.

14. Gomez,A.andGomez,A.A.(1984).Statistical Methods of Agricultural Research. John Wiley \&Sons pub, New York, USA.

15. Islam , M.D.Z.,M.A. Sattar, A.M.Uzzaman, H.M.Saud and M.K.Uddin(2012). Improvement of yield potential of rice through combined application of biofertilizer and chemical nitrogen. Afican Journal of Microbiology Research .6(4):745-750.

16. Kalitkiewicz, A. and E. Kepczynska (2008). The use of rhizobacteria to stimulate plants growth. Biotechnology 81, 102-114 (in Polish)

17. Kloepper, J.W. (2003). A Review of mechanisms for Plant Growth Promotion by PGPR. $6^{\text {th }}$ Int. PGPR Workshop, 5-10 October, Calcutta, India.

18. Mengel K., Kosegarten H. and Appel T. (2001). Principles of Plant Nutrition.Kluwer.Acad.Pub; Dordrecht.The Netherlands.

19. Neri D, Lodolini EM, Savini G, Sabbatini P, Bonanomi G and Zucconi F. (2002). Foliar application of humic acid on strawberry (cv. Onda). Proc. 1S on foliar nutrient. Eds. M. Tagliavini et al,. Acta Hort., 594: 297-302.

20. Shalaby,O.E.,M.A.El-Howeity and M.M.El-Shinnawi (2010). Wheat yield and microbial activities in newly reclaimed soil as influenced by foliar application of BioOrganic Agents. Minufiya J.Agric. Res. 35 , (2):

21. Sindhu SS, Rakshiya YS, Sahu G (2009c) Biological control of soilborne plant pathogens with rhizosphere bacteria. Pest Technol 3:10-21.

22. Stockwell VO, Stack JP (2007) Using Pseudomonas spp. for integrated biological control. Phytopathology 97:244-249.

23. Verma, J.P., Yadav J., Tiwari K.N. andV. Singh (2010). Impact of plant growth promoting rhizobacteria on crop production. INT. Agric. Res., 5:954-983

24. Vessey, J. K. (2003). Plant growth promoting rhizobacteria as biofertilizers. Plant Soil, 255:571-586.

25. Zahir, A.Z., Arhad M. and Jr. W.T Frrankenberger. (2004). Plant growth promoting rhizobacteria: Application and perspectives in agriculture. Advances in Agron, 81:97-168. 